\title{
Anclas materiales y semiótica agentiva como herramientas para la navegación y generación de sentido en el espacio geográfico
}

\author{
Material Anchors and Semiotics Agentive as tools for \\ Navigation and Sense Generation in Geographic Space
}

\section{Eduardo Gil Cañón"}

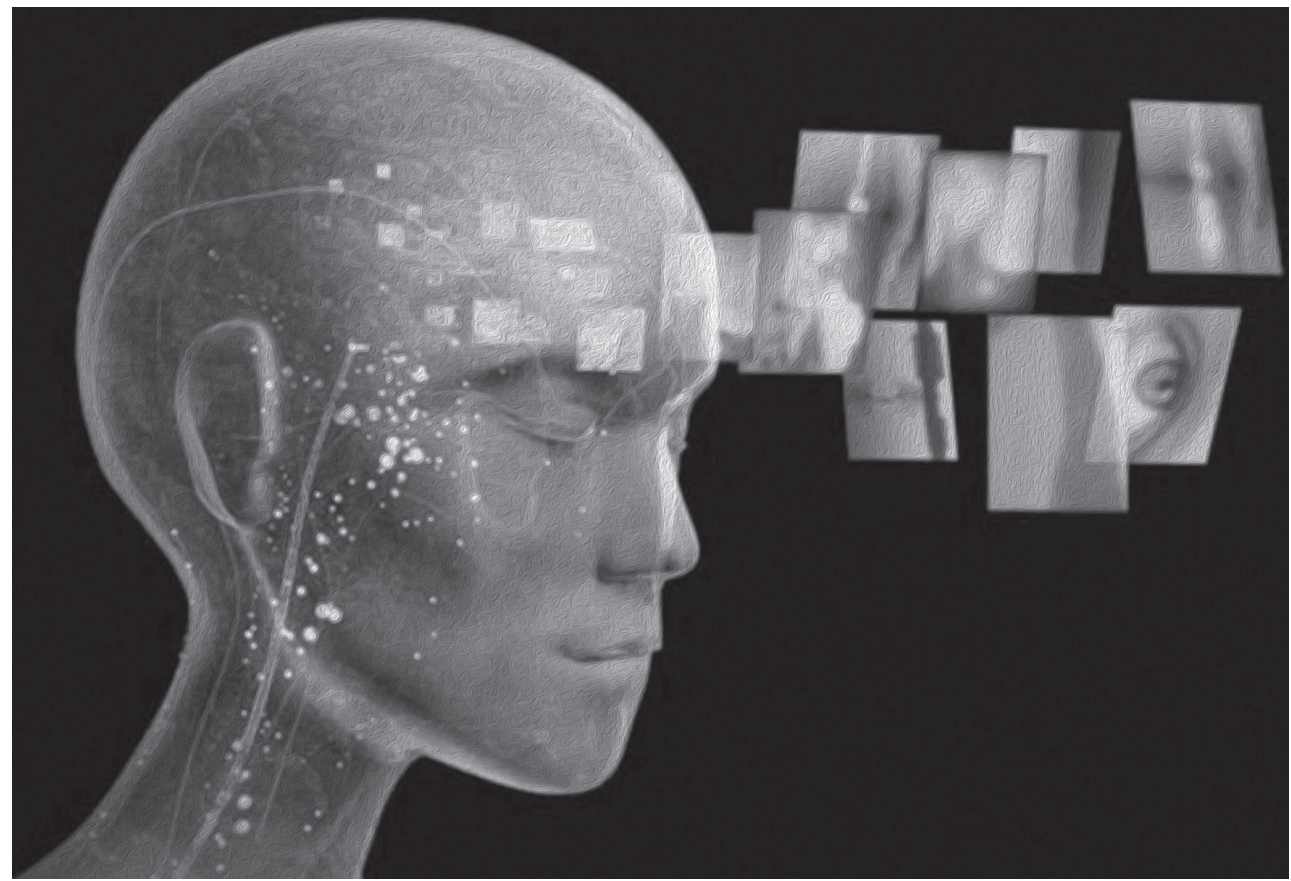

\section{Resumen}

El presente artículo intenta hacer un aporte reflexivo desde la semiótica cognitiva a la geografía humana, más específicamente a los procesos de navegación y generación de sentido de los sujetos al interior de la ciudad. La navegación por el espacio geográfico de la ciudad supone que los sujetos realicen complejos procesos de redes de integración conceptual anclados de forma material y cognitivamente con el medio

Citar este artículo como: Gil Cañón, E. (2016). Anclas materiales y semiótica agentiva como herramientas para la navegación y generación de sentido en el espacio geográfico. Revista Papeles, 8(15), pp. 37-49.

Fecha de recibido: noviembre 30 de 2015

Fecha de aceptación: marzo 1 de 2016.

* Licenciado en Educación Básica con Énfasis en Ciencias Sociales, Universidad Pedagógica Nacional. Candidato a Magister en Semiótica, Universidad Jorge Tadeo Lozano. Coordinador de Acreditación de la Licenciatura en Ciencias Sociales de la Universidad Antonio Nariño. edwardgilc@gmail.com y edwardgilc@uan.edu.co 
geográfico, donde la generación de sentido y acción local se producen de manera enactiva, esto con el fin de establecer una serie de desplazamientos con unos propósitos específicos y con la intermediación de algunos artefactos que permiten una economía cognitiva a la dación de sentido. Se hará un aporte desde los procesos de Anclas materiales-Distribución de la cognición planteados por Hutchins $(1995,2005)$ y la semiótica agentiva de Niño (2015); los cuales plantean retos para la comprensión del espacio geográfico y su generación de sentido.

Palabras clave: anclas materiales, áncoras, agente, agenda.

\begin{abstract}
This article attempts to make a thoughtful contribution from cognitive semiotics to human geography, more specifically to the processes of generation and navigation sense of subjects within the city. Navigating the geographical area of the city, means that subjects perform complex processes of conceptual integration networks anchored materially and cognitively with the geographical environment where the generation of sense and local action occur in an enactive way, this in order to establish a series of displacements with specific purposes and with the mediation of some artifacts that enable knowledge-based economy to the giving of sense. A contribution will be made from anchor materials-distribution processes of cognition raised by Hutchins $(1995,2005)$ and the agentive semiotics of Niño (2015); which pose challenges to understand the geographic space and its generation of sense.
\end{abstract}

Keywords: anchors materials, anchors, agent, agenda.

\title{
Introducción
}

La geografía ha tenido un giro significativo hacia el componente humano desde la segunda mitad del siglo XX, dejando atrás ese espacio absoluto e inamovible de la geografía física que habían institucionalizado Humboldt, Ritter, Ratzel y Richthofen, para convertirse en un espacio modificado y diverso por la acción del hombre, el cual lo transforma y lo habita. Es así como el objeto de estudio de la geografía desemboca en el espacio geográfico, siendo este "la suma indisoluble de sistemas de objetos y sistemas de acciones" (Santos, 2000, p. 88); esto implica que el hombre transfigura sus acciones y los objetos en su devenir cotidiano, estableciendo relaciones interdependientes con cada uno de los objetos que se cruza en su diario vivir. Esta perspectiva planteada por Santos (2000) permite comprender el espacio geográfico como el objeto de estudio de la geografía humana, para lo cual se busca establecer las relaciones entre los objetos estáticos/móviles del espacio con las acciones que realiza el hombre en el medio geográfico; asimismo estas acciones están orientadas al cumplimiento de un propósito, con el cual un actor social puede interpretar el espacio. También la geografía humana debe dar cuenta de cómo el hombre interactúa con los objetos en el espacio y sus propósitos de acción; pero esto es algo que no se ha abordado muy a fondo dentro de ella. Este artículo relaciona algunos aportes, por un lado, de la semiótica agentiva de Douglas Niño (2015) en relación a la generación de agendas, agentes y hábitos agentivos y, por el otro lado, de la distribución de la cognición y anclas materiales de Edwin Hutchins (1995), para desarrollar este tema del espacio geográfico en la geografía humana. 


\section{Algunos inconvenientes con la geografía de la percepción}

Al interior de la geografía humana existe una rama de explicación desde la percepción o del comportamiento (Lowenthal, 1961; Lynch, 1960; Tuan; 1974; Estébanez, 1979; Millán, 2004; Recques, 2006), donde la percepción del medio se realiza a través de una serie de imágenes mentales, que van acompañadas de una serie de actos que permiten la apropiación del espacio en relación con los sujetos que se desplazan por el medio. Desde esta perspectiva, Recques (2006) menciona que existen dos líneas de acción: una que habla sobre la geografía desde la perspectiva del comportamiento, en la cual se encuentran estudios sobre modelos de desplazamiento en relación a localización, trayectos y distancias de los sujetos, representados en mapas mentales; otra línea con una perspectiva humanista, que hace referencia a las subjetividades e intersubjetividades que se encuentran en el espacio vivido, en donde los valores culturales y sociales permiten reconocer la importancia del papel de los símbolos y significados que imprimen los sujetos al espacio.

Estas líneas de acción permiten comprender la geografía de la percepción como las representaciones mentales que hacen los sujetos de su espacio vivido, y a partir de estas poder establecer sus trayectos o resolver problemas de espacialización cotidiana. Asimismo, el espacio se carga con unos valores y subjetividades propias de los individuos, las cuales les permiten apropiar y desenvolverse en el espacio. De esta manera, el espacio geográfico al interior de la geografía de la percepción "no solamente está fuera de nosotros con una existencia física que le pertenece, sino que también está dentro de nuestras mentes" (Bosque et al, 1992, 8); en donde interactúan los sujetos con el espacio exterior a través de las representaciones mentales que han sido elaboradas por la cotidianidad de sus vidas.

Ahora bien, un espacio geográfico por excelencia de la geografía de la percepción es la ciudad, en cierta medida porque esta es la raíz de los procesos de crecimiento urbano, convirtiéndola en un lugar y enfoque de estudio. En ella se dan múltiples relaciones entre los sujetos y el espacio, también se califica la calidad de vida de las personas y los procesos de ubicación (Bosque et al, 1992). Es así como muchos de los estudios en geografía de la percepción desde las líneas planteadas por Recques han trabajado y abordado la ciudad desde sus representaciones mentales y los valores que se imbrican en ella.

Uno de los precursores en trabajar la ciudad desde las representaciones mentales de la ciudad es Kevin Lynch (1960). Su discurso gira entorno de las imágenes ambientales y el desplazamiento de los seres humanos por la ciudad, estableciendo unos hitos o puntos de referencia. Esta perspectiva estaría ubicada desde la línea de la geografía del comportamiento. Otro de los primeros en trabajar la geografía de la percepción, pero desde una aproximación humanista, es Yi-Fu Tuan (1974). Para él, la noción de lugar es muy importante. Tuan hace un estudio sobre los valores y las subjetividades con las cuales los seres humanos cargan el espacio geográfico, es allí donde las relaciones afectivas de los sujetos con el espacio construyen sus representaciones mentales.

En el presente artículo se abordarán estas dos perspectivas, pues Kevin Lynch hace un aporte importante sobre los hitos que utilizan los sujetos para crear sus mapas mentales, lo cual permite hacer una contribución desde la distribución de la cognición para explicar cómo se dan esos procesos cognitivos, pero asimismo, cómo estos son anclas materiales que permiten la ubicación y desplazamiento de los sujetos. Por su parte, la contribución de Yi-Fu Tuan sobre los valores en el espacio permite profundizar desde la semiótica agentiva cómo los sujetos establecen unas agendas 
para determinar sus recorridos y cómo actuar ante ciertas situaciones en el espacio. Esto con el fin de comprender cómo le damos sentido al espacio geográfico.

A continuación se presentarán algunos de los postulados de cada uno de los autores anteriormente mencionados, explicando que al interior de los aportes teóricos de la geografía de la percepción se encuentra una serie de fallos en relación a la comprensión de las acciones y propósitos de los sujetos en el espacio, además cómo estos interactúan con el espacio físico por medio de ciertos elementos cognitivos. Posteriormente, se explicarán algunos aportes de la semiótica agentiva (Niño, 2015), la distribución de la cognición y anclas materiales (Hutchins, 1995) a la geografía de la percepción.

\subsection{Imágenes de la ciudad}

Hablar del espacio geográfico implica también reconocer la importancia de las ciudades, puesto que al ir creciendo las ciudades como medio físico y el aumento de la población en ellas, se establece otra perspectiva de la geografía, donde los habitantes de la ciudad crean espacios propios e imágenes para movilizarse, convirtiéndose en una geografía de las ciudades. De esta manera, Kevin Lynch (1960), en su trabajo "La imagen de la ciudad", explica que "la ciudad no es solo un objeto que perciben millones de personas de clases caracteres sumamente diferentes, sino que es también el producto de muchos constructores que constantemente modifican porque tienen sus motivos para ello" (p. 10). Con esto, la ciudad sufre modificaciones constantes por los que la habitan y transcurren, siendo la ciudad un constructo de los habitantes, los cuales por medio de propósitos la modifican y perciben constantemente.

Lynch (1960) habla de las imágenes ambientales de la ciudad, las cuales "son el resultado de un proceso bilateral entre el observador y su medio ambiente. El medio ambiente sugiere distinciones y relaciones, y el observador [...] escoge, organiza y dota de significado lo que ve" (p. 15). Esto conlleva a que los sujetos van creando imágenes de los elementos constitutivos de la ciudad, pero al mismo tiempo las organizan para desplazarse dentro de ella y les imprimen un significado. El problema de estas imágenes ambientales radica en que no se explican las razones por las cuales un habitante de la ciudad escoge y organiza esa serie de elementos del espacio para desplazarse. Así mismo, tampoco se explica cómo lo dota de significado, o mejor aún, cuáles son las condiciones que permiten dotar de significado un espacio de la ciudad. Tampoco logra explicar cómo se crean esas imágenes dentro del proceso cognitivo del observador, ni cómo se activan esas imágenes para que el observador se pueda mover por la ciudad.

Ahora bien, para Lynch (1960) esas imágenes ambientales de la ciudad son plasmadas en unos mapas cognitivos que el observador elabora de la ciudad, estos mapas tienen tres partes analíticas: identidad, estructura y significado. La identidad hace referencia a la identificación de los objetos como entidades únicas y separadas, la estructura implica relaciones entre los objetos ubicados en el espacio de forma estática y el significado es el que los observadores le atribuyen a los objetos y relaciones entre ellos de manera práctica. Pero aún quedan vacíos dentro de su explicación, como por ejemplo, ¿la identidad, estructura y significación son procesos cognitivos para la creación de los mapas mentales de la ciudad? Si es así, cómo se activan en el proceso de caminar por la ciudad. Además, hablar de significado unido a la identidad de los elementos conlleva entender que los elementos contienen un significado en relación a una forma y un contenido de la semiótica tradicional, pero no se explica cómo los sujetos dotan de sentido a lo que hacen en la ciudad por medio de esos elementos, puesto que la significación de la ciudad puede variar dependiendo de cada sujeto. 
Por otra parte, Lynch (1960) establece algunas herramientas para el trabajo de la percepción de la ciudad, como lo son sendas, bordes, barrios, nodos, mojones e hitos. Por ejemplo, las sendas son "los conductos que sigue el observador normalmente, ocasionalmente o potencialmente. Pueden estar representadas por calles, senderos, líneas de tránsito, canales o vías férreas" (p.62). Esto implica que el sujeto solo se desplaza por medio de calles configuradas, pero qué sucede cuando se cruza por un parque o un centro comercial, donde las líneas de tránsito no son definidas o que son definidas por el propio sujeto en su proceso de desplazamiento. Es así que la navegación al interior de la ciudad por dichas sendas no es explicada ni cómo se da la configuración de sentido en esas sendas, puesto que, esas sendas pueden no ser transitadas por ser reconocidas por el sujeto como inseguras.

\subsection{Lugares afectivos}

Ahora bien, dentro de la geografía de la percepción, Yi-Fu Tuan (1974) con su obra "Topofilia. Un estudio de las percepciones, actitudes y valores sobre el entorno", explica cómo funcionan los aparatos preceptivos del ser humano, dando prioridad a la visión en la construcción de significados de un espacio, ligando esto a la capacidad olfativa de algunos lugares. Para él la percepción es:

La respuesta de los sentidos a los estímulos externos como el proceso específico por el cual ciertos fenómenos se registran claramente mientras otros se pierden en las sombras o se eliminan. Mucho de lo que percibimos tiene valor para nosotros, tanto para nuestra supervivencia biológica como para brindarnos ciertas satisfacciones que están enraizadas en la cultura (Tuan, 1974, p. 13).

Esta descripción pretende unir la percepción a un valor y una actitud corporal frente a lo que estamos percibiendo del mundo exterior.
Esto conlleva a generar un sentimiento de apropiación del espacio, pero al mismo tiempo un distanciamiento de ciertos espacios que le son ajenos a los sujetos, pues las experiencias perceptivas enseñan algo sobre los valores y actitudes que se deben tomar frente al espacio. Ligado a esto está el carácter evocativo de los espacios, ya sea por los olores, imágenes u objetos que están en él, donde la memoria cumple un papel importante en la creación de espacios que son agradables o desagradables.

Lo anterior es interesante para comprender los valores que plasman los sujetos en su espacio vivido, pero surgen algunas preguntas sobre cómo la percepción puede guiar el comportamiento humano en el espacio de la ciudad. Es necesario comprender cómo funciona la generación de sentido local, para que el ser humano pueda localizar los espacios y saber cómo actuar en determinado momento. Por otra parte, Tuan desarrolla la idea de las topofilias, que son los lugares que representan el agrado que sienten las personas en un lugar, aplicándole ciertos valores y actitudes positivas dentro del espacio, como él menciona:

La topofilia no es la más fuerte de las emociones humanas. Cuando llega a serlo, podemos estar seguros de que el lugar o el entorno se han transformado en portadores de acontecimientos de gran carga emocional, o que se perciben como un símbolo (Tuan, 1974, p. 130).

El espacio geográfico se convierte en un símbolo de las experiencias vividas por los sujetos, el cual está cargado emocionalmente; ahora las experiencias pueden ser positivas entendidas como topofilias, pero también abre la puerta a las experiencias negativas que convierten el espacio en un lugar de desagrado, algo que podría ser llamado topofobias. Pero otra vez vuelven a surgir dudas, como qué sentimientos y lugares se integran dentro las topofilias, o qué acontecimientos, percepciones y motivaciones se integran para que un sujeto se desplace a un lugar o no. 


\section{Posibles aportes de semiótica agentiva y distribución de la cognición}

Para ir dando solución a los anteriores fallos dentro de la geografía de la percepción, se encuentra un gran aporte desde la semiótica agentiva, la distribución de la cognición y en el anclaje material para el pensamiento del espacio geográfico. De esta manera, se retomará por un lado lo propuesto por Hutchins $(1995,2005)$ frente a la distribución de la cognición en el espacio y por otro lado a Niño (2015) sobre la estipulación de agendas, para comprender los procesos de navegación y generación de sentido en la ciudad. Como punto de encuentro de ambas posturas se hablará sobre anclas materiales y áncoras que permiten comprender los procesos cognitivos en el espacio para su desplazamiento. Esto con el fin de mostrar que para analizar el espacio geográfico es importante trabajar la cognición y la creación de agendas dentro de la navegación que realizan los sujetos, ya sea on-line/on-going o desde la planeación de rutas imaginarias de su cotidianidad, en el cual el anclaje material permite afianzar una ruta en el espacio. De esta manera, dotar de significado potencial, es significar la ciudad en el proceso de dación de sentido, significación implica actualizar el espacio en relación a unas agendas propias.

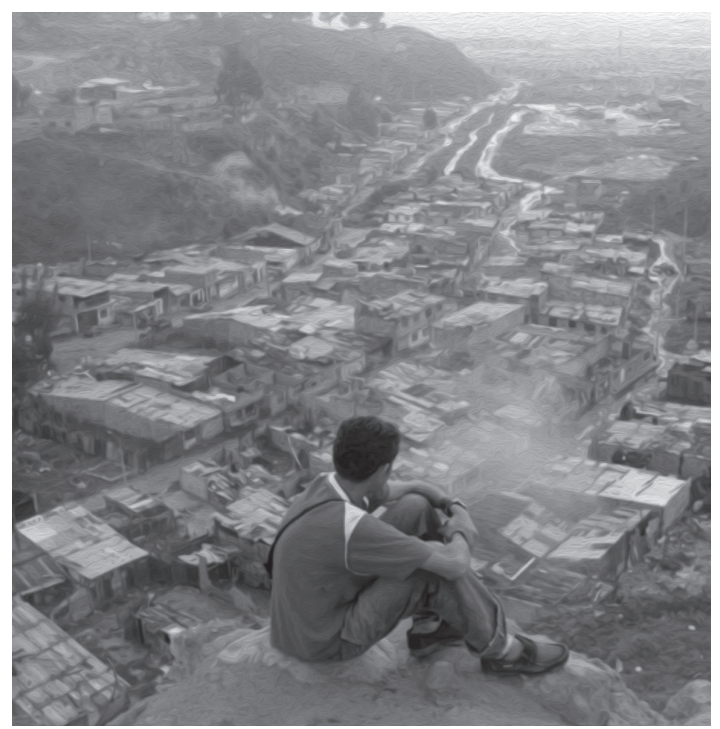

\subsection{Distribución de la cognición en el espacio}

En primera medida se trabajará la distribución de la cognición. Este aporte teórico de Hutchins (1995) ayuda a comprender cómo la navegación interrelaciona objetos externos del espacio con procesos cognitivos que permiten la localización y desplazamiento de los sujetos. Es así que para Hutchins los cálculos básicos de navegación se caracterizan por la representación algorítmica y la representación observable del espacio, donde los sistemas cognitivos se comunican entre los actores como procesos internos. Los medios de cálculos pueden ser representados en diagramas o gráficos, con los cuales se representa el sistema cognitivo interno (Representación algorítmica); y la actividad cognitiva está distribuida entre la red social con los procesos internos y las comunicaciones internas que son directamente observables (representación observable). La navegación -para este caso en particular de la "ciudad"-, comprende dos procesos de representación que no están separados ni desligados el uno del otro. Un primer aporte está en que la creación de una imagen ambiental contiene la representación algorítmica de un espacio geográfico en mapas o gráficos de la ciudad que representa el sistema cognitivo interno, al igual que la representación observable constituye las relaciones e interacciones de los sujetos con cada uno de los elementos del espacio como una actividad cognitiva.

En esa línea, la fijación de una posición implica la manipulación e interrelación entre representaciones y herramientas externas con las cuales los sujetos constantemente realizan tareas, ya sea de forma individual o en grupo, conllevando a la transformación de los insumos de los cálculos de navegación. Con lo anterior, la navegación es una actividad física real llevada por individuos en la manipulación de 
objetos físicos reales; estos son símbolos que representan la proyección de una posición en relación a un gráfico, para lo cual es necesario tener una estructura interna mínima para la realización de una serie de tareas (Hutchins, 1995). Nótese aquí otro aporte a las imágenes ambientales, puesto que no solo contienen un significado para los habitantes de una ciudad, sino que permiten la navegación a través de la manipulación de las representaciones -algorítmica y observable-con herramientas del espacio, en el establecimiento de tareas a cumplir dentro del espacio, como llegar a la escuela, ir al trabajo, o localizar un punto de referencia para ubicarse en la ciudad.

Ahora bien, esas herramientas del espacio son objetos físicos externos del mundo, pero que al mismo tiempo son juicios conceptuales e inferencias perceptuales internas del medio. Esto quiere decir que los procesos cognitivos para la navegación implican la interrelación entre la manipulación de un sistema de artefactos tanto internos como externos, en relación con unas representaciones tanto internas como externas, que se convertirán en "artefactos cognitivos" de la navegación (Hutchins, 1995).

Por otra parte, el proceso de formar una interpretación del espacio geográfico se puede entender como la elaboración de una hipótesis de navegación y la evidencia en el mundo real. Estas hipótesis permiten la generación de redes de conexión en un modelo de interpretación individual, en donde se establecen tres variables de comportamiento: 1) Redes de esquema del fenómeno sobre el cual la interpretación está formada; 2) Redes de preconcepciones sobre el estado en el mundo, siendo las interpretaciones sobre el espacio donde las redes empiezan; $y, 3)$ Redes de espacios de entrada externos (Hutchins, 1995). Con esto, las imágenes ambientales creadas por los sujetos son redes de interpretación que le facilitan su proceso de desplazamiento al interior de la ciudad.
Lo anterior plantea que las imágenes ambientales pueden establecer tres variables de comportamiento en el espacio de la ciudad; por un lado, las interpretaciones ya establecidas por un sujeto del espacio de la ciudad, que le permite desplazarse por una ruta de navegación; por otro lado, establecer rutas de navegación por una preconcepción del espacio; por último, la interpretación de objetos externos. Este concepto de redes se refiere a la creación de mapas mentales de una gran variedad de interpretaciones del mundo, que permite la interconexión entre otras redes, ya sean internas o externas, para una mayor configuración de información sobre el espacio y las actividades a realizar en él (Hutchins, 1995).

En ese proceso de navegación, una experiencia secuencial de estas redes permite que se aprendan las secuencias almacenadas en la memoria para convertirlas en una habilidad/ hábito, las cuales vuelven sin la necesidad de una estructura de mediación, sino que se hacen presentes en el mundo. Esto lleva a comprender la memoria en tres sentidos; 1) léxica, en donde se guardan los pasos; 2) semántica, donde se guardan los significados de los pasos, y 3) motora, donde se realizan procesos de hábitos (Hutchins, 1995). De esta manera, los sujetos en el espacio usan su memoria como medio de navegación por el espacio de la ciudad, donde almacenan los recorridos a seguir, los cuales tienen un significado potencial para ellos y por medio de las habituaciones que realizan de estos.

Esto conlleva que la mente humana encuentra y proyecta regularidades para el desarrollo de una serie de tareas en el ambiente, donde la anidación de lecturas de dichas representaciones como un dispositivo de observación permite determinar las direcciones, medidas y ángulos sobre las cuales se va fijar un desplazamiento en resolución de una tarea, generando una serie de habilidades aprendidas sobre el espacio, que en cierta medida han sido habituadas (Hutchins, 1995). 
Bajo esta perspectiva de hábitos aprendidos del espacio, es necesario hacer un salto (por ahora) a la semiótica agentiva, puesto que presta atención a los procesos atrincherados que se van convirtiendo en hábitos, permitiendo comprender cómo se generan esos hábitos y tener una visión más amplia de ellos. En esa línea, Niño (2015) explica que existe un hábito agentivo, el cual:

emerge a partir del intento repetido (sea o no exitoso) de lograr un objetivo. En este sentido, con un acto agentivo, un agente además de estar intentando dar cumplimiento a su meta, normalmente estará aprendiendo, modificando, extendiendo, puliendo, etc., un hábito agentivo (o varios), y de este modo estará reforzando, por así decirlo, formas 'preempaquetadas' de dar sentido (Niño, 2015, p. 74).

Esto hace que el proceso de navegación pueda ser habitualizado agentivamente por los sujetos, donde el recorrer la ciudad por una ruta constante, ya sea para ir a la casa o al trabajo o a la escuela, en fin, cualquier meta dentro de la ciudad, puede estar habitualizada por ser repetitivo en la consecución de estas metas. De esta manera, otro aporte a la geografía de la percepción es que desplazarse por la ciudad tiene una forma pre-empaquetada de darle sentido a su recorrido, los sujetos activan esos pre-empaquetados para navegar por la ciudad que les es cotidiana y propia.

Otro apunte dentro de la semiótica agentiva frente a esta habituación del espacio geográfico es frente a la "perspectivización de la dación de sentido, es decir, debido al progresivo 'atrincheramiento', se resulta resaltando algunas cosas y se dejan de lado otras. Esto también significa que los hábitos agentivos también prescriben y proscriben" (Niño, 2015, p. 75). Esto ayuda a comprender la razón del porqué las imágenes ambientales de los agentes tienen mayor prelación por resaltar unos hitos de referencia sobre otros, donde se resaltan algunos elementos del espacio y otros son dejados atrás sin percatarse de su existencia. De igual manera, ayuda a comprender las categorías de sendas, bordes, mojones, etc., las cuales dependen del nivel de atrincheramiento del sujeto para resaltarlas o pasarlas por alto, siendo para cada individuo una forma diferente dentro de su proceso de navegación.

\subsection{Establecimiento de agendas}

$\mathrm{Al}$ interior de la anterior explicación subyace la idea de agendas de Niño (2015) como parte fundamental dentro de la navegación de los sujetos. De forma exploratoria se explicará la noción de agendas planteada desde la semiótica agentiva.

\subsubsection{Agendas}

La semiótica agentiva permite ampliar las nociones de roles, en relación al establecimiento de agentes, agencias y agendas para el proceso de navegación de la ciudad como un espacio geográfico de los sujetos que la habitan. Esto conlleva a especificar cada una de las terminologías al interior de la teoría e irlas relacionando con lo planteado por Hutchins y su valor como aporte a la geografía de la percepción. Para lo cual, lo primero que se debe tener claro es la noción de agente y agenda:

Agente es, literalmente, un 'ente activo', con lo que queremos decir, un ente que hace o que puede hacer. Ahora bien, se puede decir que tanto el agente como lo que hace, esto es, sus actos, 'tienen objetivos', o de un modo más preciso, se orientan hacia un cierto tipo de resultado que llamaremos agenda (Niño, 2015, p. 38).

Agregando a lo anterior, un agente es cualquier entidad con animación, situacionalidad y atención, que tiene una capacidad para desarrollar una serie de actos/acciones, es decir, una agencia propia o conjunta para el cumplimiento de una meta. A raíz de esto, Niño (2015) habla 


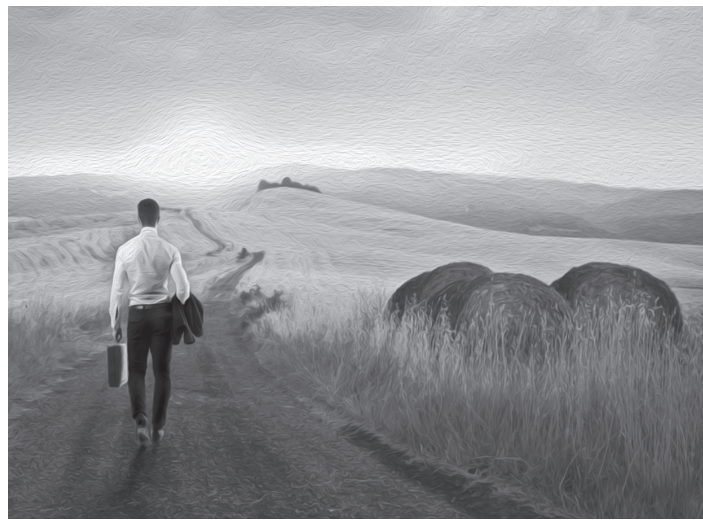

de una agencia primaria, una operativa y una derivada. La primera es "entendida como la capacidad para actuar de un agente" (p. 40) y la segunda es "la puesta en marcha de dicha agencia por esos seres en sus acciones y actos concretos, que llamamos agencia operativa" (p. 40). Aquí el aporte reside en que una agencia es la capacidad que tiene un habitante de la ciudad para actuar en ella, y agencia operativa es la que el sujeto desarrolla constantemente, puesto que implica la enacción de un sujeto on-line, por ejemplo, mientras se desplaza hacia un lugar, nuestro cuerpo va realizando una serie de acciones para poder cumplir con la meta de llegar a un punto determinado, es decir, caminar, observar el medio, interactuar con otra persona mientras se llega al punto determinado.

Con lo anteriormente mencionado, se puede hacer un proceso de analogía con la categoría de tareas de Hutchins (1995) que se mencionó someramente, puesto que algunas de las agendas implican un plan de acción ${ }^{1}$ por parte de un agente para el cumplimiento de una tarea/meta. Pero para el desarrollo de esa tarea existen unas pautas a seguir frecuentemente; esas pautas a seguir se complementan con una agencia operativa. Por ejemplo, si

1 Douglas Niño (2015) menciona al respecto que: "hay agendas que incluyen como parte de su cumplimiento una cierta planeación previa (recuérdese lo mencionado anteriormente sobre el control), mientras que hay otras que no lo incluyen" (p. 98). la tarea es "llegar temprano al colegio", para el cumplimiento de esta, el estudiante debe establecer una serie de condiciones tanto operativas como de planeación para cumplirla. Entonces, ambas nociones no son tan incompatibles, pero tiene mayor desarrollo y valor teórico para este caso el reconocimiento de agendas y agentes que se pueden identificar en el espacio.

Volviendo al tema de las agencias, la agencia derivada es "aquella que por convención o hábito hemos aprendido a interpretar como si tuviera sentido [...] este es asignado por la agencia de un agente o un conjunto de agentes, pero en sí misma y por sí misma no hace sentido" (Niño, 2015, p. 40). Esta agencia nos explica cómo al ir interiorizando una serie de acciones constantemente se vuelven hábitos que el mismo agente o los agentes han reconocido/aceptado, la cual tiene un plan estipulado para el comportamiento de las personas; pero solo se establece en la medida en que la agencia operativa la requiere para darle sentido. Por ejemplo, en la ciudad a un semáforo le asignamos una agencia en relación a los actos que se deben realizar frente a cada uno de los colores, pero solamente cuando el agente presta atención al semáforo es que le da sentido en relación a las acciones que debe realizar si está en rojo, amarillo o verde, lo cual integra a su agencia operativa para cumplir con su agenda de llegar al colegio.

De acuerdo con las agendas y los actos/acciones de un agente, surgen ciertos efectos que pueden modificar o esperar a que una agenda se cumpla, para lo cual Niño (2015) introduce los conceptos de per-agendas, dil-agendas, perefectos, dia-acciones y dia-actos. Esto ayuda a explicar los casos en los que una agenda puede ser modificada por la agenda de otro agente o se espera que se cumpla el efecto de una agenda. Esto busca reconocer la importancia de los efectos que pueden causar en la navegación de los sujetos, las acciones/actos de los demás agentes; puesto que pueden modificar las condiciones de navegabilidad y generación 
de sentido a las rutas que establecen los agentes para llegar a un punto determinado. Este tema dentro de la geografía comportamental no se tiene en cuenta en la creación de las imágenes ambientales del medio, puesto que el esperar que una agenda se cumpla - paso a paso- o que otro agente intervenga, conlleva a que mi ruta sea modificada o validada.

Esto nos lleva a realizar una diferenciación muy importante entre asignar y atribuir agencia, como parte de los procesos que realiza un agente en su navegación:

Habrá que distinguir la asignación de agencia, que tiene como efecto el generar una agencia derivada, de la atribución de agencia, que quiere decir que se trata a algo como si 'tuviera agencia'. En el primer caso, un agente o un conjunto de agentes asignan funciones a objetos o signos, como en el caso de un diseñador; mientras que en el segundo se atribuye alguna clase de agencia a algo: intrínseca, si lo que hacemos es atribuir a lo que nos sale al encuentro agencia intrínseca, como cuando atribuimos la capacidad de actuar a alguien o a algo; operativa, como cuando atribuimos a alguien la intención de realizar o haber realizado una acción; y derivada, como en el caso mencionado del reconocimiento de la función de un objeto de diseño (Niño, 2015, p. 41).

Aquí observamos una relación con lo mencionado por Hutchins (1995) con respecto a la manipulación de objetos y representaciones del medio. Por un lado, asignar una agencia implica a los objetos de manipulación para la navegación, y al igual que a las representaciones del medio que se tienen; por otro lado atribuimos agenda al proceso de interactuar para el cumplimiento de detectar un punto de referencia, es así como confiamos en las capacidades de otro agente el cual nos permite cumplir nuestra propia agenda.

Todo esto nos lleva a comprender que la geografía de la percepción debe estar encaminada a establecer los agentes y agendas dentro de la ciudad, para de este modo conocer la forma de navegar por la ciudad. De esta manera, el espacio geográfico adquiera significado para los agentes en su proceso de actuar en el mundo, dejando de ser absoluto y cargado de significación igual para todos los agentes. Donde las razones de su desplazamiento se encarnan en las agendas que llevamos constantemente en nuestras vidas, y permite significar de maneras diferentes el espacio.

\subsection{Anclajes materiales en el espacio}

Por otra parte, la noción de anclas materiales desarrollada por Edwin Hutchins (2005) es una forma de estabilizar las integraciones conceptuales que realizan los sujetos en relación a las estructuras materiales que existen el medio ambiente; al igual, Douglas Niño (2015) retoma esta noción para establecer la noción de anclaje material y áncoras dentro de su teoría de semiótica agentiva, con las cuales se puede establecer algunos aportes a los hitos, sendas y mojones en relación a su forma cognitiva de ser utilizadas y darle sentido, pero también a la comprensión de la activación de topofilias; estos serán expuestas a continuación.

\subsubsection{Anclas materiales}

Para Hutchins (2005), las anclas materiales son elementos materiales perceptibles con los cuales se pueden construir espacios mentales, es así como "the selective attention to, and projection of structure from the material world to the blended space is the perceptual process. That is, that selective perception is a conceptual process" ${ }^{\prime 2}$ (p. 1561); al establecer una estructura material con el medio también se establecen estructuras conceptuales del

2 "la atención selectiva, y la proyección de la estructura del mundo material a un espacio integrado es el proceso de percepción. Es decir, que la percepción selectiva es un proceso conceptual" (traducción del autor). 
medio, que serán proyectados en el espacio mental de los individuos.

Bajo esta perspectiva los espacios de entrada reclutan información conceptual, pero esta información de elementos conceptuales, también recluta una estructura material que permite anclar y estabilizar los espacios mentales. Hutchins (2005) menciona que "a mental space is blended with a material structure that is sufficiently immutable to hold the conceptual relationships fixed while other operations are performed"3 (p. 1562). El aporte a la creación de imágenes ambientales reside en que ellas son espacios mentales integrados, en los cuales existe una estructura material y conceptual para su elaboración y navegación en el espacio geográfico. Esto puede verse reflejado, por ejemplo, cuando hablamos del Congreso de la República de Colombia, ya que nos permite anclar un espacio físico real en relación a unos edificios, personas, objetos reales, etc.; pero también permite reconocer conceptualmente como un lugar en donde se discuten y crean las leyes del país. Es así como configurar los elementos como propiedades físicas en un espacio determinado, en relación a una serie de ancla materiales, permite estabilizar los elementos desde las estructuras conceptuales que poseemos de los mismos.

Frente a esto, Niño (2015) explica que "el ancla material, por su misma naturaleza perceptible, permite anclar puntos de referencia espaciales o espacio-temporales que sirvan como ingredientes en la construcción de espacios mentales" (p. 288); esto sería otro aporte para comprender el concepto de "palimpsesto" que subyace en la geografía de la percepción, el cual hace referencia a que para ciertos sujetos un espacio modificado puede traer a su memoria el espacio antiguo e integrarlo de forma tal

3 "un espacio mental se integra con una estructura de material que es suficientemente inmutable para mantener las relaciones conceptuales fijas mientras que otras operaciones se realizan" (traducción del autor). que pueda reconocer no solo el espacio sino la relación espacio-temporal de los objetos de la ciudad.

Las anclas materiales pueden ser reconocidas como un hito dentro del espacio geográfico en la medida que un hito se entiende como un nodo, es decir, son "puntos estratégicos de una ciudad a los que puede ingresar un observador y constituyen los focos intensivos de los que parte o a los que se encamina" (Lynch, 1960, 63). Al igual, Niño (2015) resalta que las "anclas materiales en los que sus características presentan saliencias para la atención - como el rasgo 'esferoide' para el papel arrugado del juego de los estudiantesque facilitan la interpretación, exploración y manipulación de esas mismas anclas materiales" (p. 288). De esta manera, localizar la señal correcta en el mundo de un "hito" implica que la descripción del mismo debe contener el conocimiento de la apariencia y la coordinación con un campo visual, es decir, debe haber una conexión entre la descripción de destino con un tipo de información en el medio.

Asimismo, los elementos de descripción, ya sean imágenes o estructuras simbólicas, se constituyen un proceso de aprendizaje en el desarrollo de un proceso altamente interactivo; la representación es una escena visual en el reconocimiento del nombre, las expectativas que se "constraint" en el hito. Esta escena visual de la imagen mental y la representación del hito se superponen interna y externamente, como medio de representación de la propia señal como una mejora del mapa mental en relación a los procesos de memoria y asociación descriptiva (Hutchins, 1995).

\subsection{Afectividad en el espacio}

Por último se explicará cómo la semiótica agentiva aporta a la comprensión del espacio geográfico como lugar de afecto o desagrado. De esta manera se examinará brevemente la noción de áncoras de Niño (2015), las cuáles 
son anclas materiales que han sido institucionalizadas para comprender las relaciones en el espacio; de esta manera van a existir lugares y contextos que se anclan para comprender los roles y agendas que se van a determinar en un espacio. Esta noción de áncora se une a las relaciones de afectividad en el espacio, aportando a comprender cómo se activa una topofobia o topofilia.

Las topofilias se definirían como el agrado por un espacio, ya sea a nivel kineto-perceptivo o del recuerdo de imágenes frente a ese lugar. De igual manera, la topofobia implica el desagrado que se puede generar frente a un lugar, también desde lo kineto-perceptual o de la memoria de un espacio (Tuan, 1974). Estas definiciones carecen de sentido al entrar en el mundo de las percepciones/recuerdos sin explicar su proceso de activación por parte de un agente, puesto que al ser categorías subjetivas, la dación de sentido puede variar de agente en agente. Por esta razón las nociones de arousal y valencia tomadas de la semiótica agentiva abren a otro tipo de formas de comprender el espacio geográfico como medio de dación de sentido, por el cual actúa un agente, puesto que un parque para un agente puede ser un espacio de miedo o desagrado como también lo puede ser de agrado y gusto.

De esta manera, "El arousal se refiere al grado de vivacidad que un agente presenta en un momento dado" (Niño, 2015, p. 55); este grado de activación que un agente puede establecer frente alguna actividad externa/interna desencadena una serie de emociones con respuesta hacia los "sistemas motores eferentes: locomotor, facial, vocal, autonómico y hormonal que garantizan una respuesta apropiada" (ChayoDichy, 2003, 214). Es así como la activación del arousal conlleva a una respuesta apropiada en un espacio determinado, donde "los patrones de activación, apoyan acciones específicas en respuesta a amenazas ambientales o bien en el caso de emociones positivas, apoyan acciones que permiten enfrentar oportunidades" (León, 2014, 58).
Con lo anterior, la topofilia o topofobia depende del nivel de activación de una persona frente a un estímulo, generando una serie de respuestas conductuales en el espacio. El arousal puede ser alto o bajo dependiendo del estímulo que se pueda generar en un agente. Es así como el espacio geográfico puede generar una exaltación o excitación (Arousal Alto), frente a una quietud o calma (Arousal Bajo) en los sujetos. Por ejemplo, la topofilia contiene un arousal alto frente a un estímulo en el espacio, puesto que un lugar en el cual se genera un afecto activará de forma rápida recuerdos y emociones afectivas positivas; lo mismo sucederá con la topofobia, en donde un espacio de miedo activará una actividad motora con una agenda para tratar de evitarlo, cambia su disposición frente al espacio y sus agendas en curso. De igual manera, un arousal bajo puede ayudar a comprender por qué las personas pasan por un lugar de forma indiferente frente a lo que se ve en el ambiente; por un lado, el espacio está atrincherado, pero por el otro no genera ninguna activación o exaltación en el espacio; aunque un efecto de sorpresa en ese espacio interiorizado y atrincherado puede activar un arousal alto, ya sea por una topofilia o topofobia.

Por último, es necesario hablar sobre la categoría de valencia, esto quiere decir que las "emociones primarias tienen valencia positiva

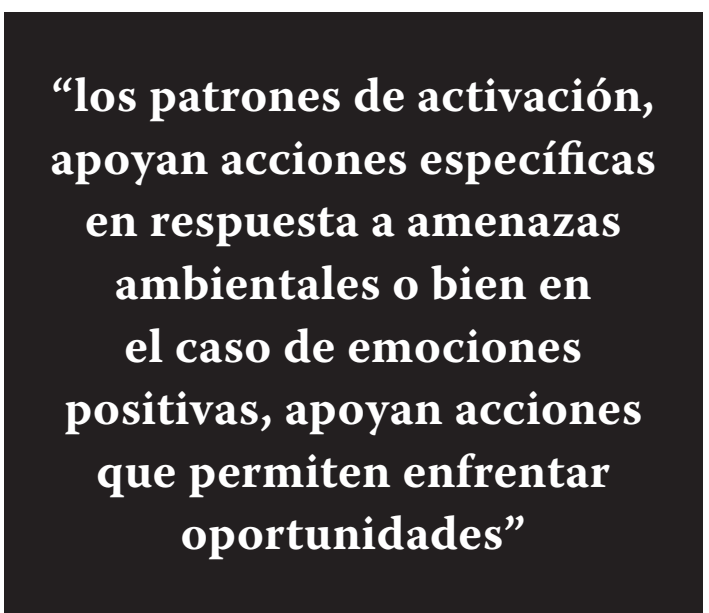


(por ejemplo: alegría, interés) o negativa (por ejemplo: ira, miedo, pánico, tristeza, disgusto)" (Chayo-Dichy, 2003, 215), llevando a entender la topofilia como una valencia positiva y la topofobia como una valencia negativa. Asimismo, las emociones marcadas en el espacio contienen una valencia afectiva, que tiende a estar en relación con la experiencia vivida, la cual marcamos con valores de felicidad, tristeza, amor, miedo, entre otros; puesto que el espacio en donde un agente tenga una experiencia agradable se convertirá en una valencia positiva, es decir, un topofilia; mientras que si la experiencia fue desagradable tendrá una valencia negativa, en esa medida será una topofobia.

\section{Referencias}

Bosque, J; et al (1992). Prácticas de geografía de la percepción y de la actividad cotidiana. Barcelona, Editorial Oikos.

Capel, H. (1973). Percepción del medio y comportamiento geográfico. Revista de geografía, 6, 50-150

Chayo-Dichy, R, et al. (2003). Valencia, activación, dominancia y contenido moral, ante estímulos visuales con contenido emocional y moral: un estudio en población mexicana. Revista española de neuropsicología, 5(3-4), 213-225.

Estébanez, J. (1979): "Consideraciones sobre la geografía de la percepción”, Paralelo 37, № 3 , págs. 5-22.

Hutchins, E. (1995). Cognition in the Wild. Cambridge, MA: MIT Press.

Hutchins, E. (in press). Cognitive ecology. Topics in cognitive science. Recuperado de: http://hci. ucsd.edu/234/234ExtraReading/A63CognitiveEcologyFinal.pdf el 5 de febrero de 2015

Hutchins, E. (in press). Distributed cognition. Recuperado de: http://gnowledge.org/ sanjay/ Advanced_Cogsci_Course_2015/Week3/ Week3_DistributedCognition_1.pdf el 5 de febrero de 2015

Hutchins, E. (in press). Enaction, imagination, and insight. In enaction: towards a new paradigm in cognitive science. Cambridge, MA: MIT Press.

Hutchins, E. (2005). Material anchors for conceptual blends. Journal of Pragmatics, 37, 1555-1577.

León, D. (2014). Emociones en la vejez: Diferencias asociadas a la edad (tesis doctoral).
Departamento de Psicología Biológica y de la Salud, Facultad de Psicología Universidad Autónoma de Madrid, Madrid.

Lowenthal, D. (1961). Geography, experience and imagination: towards a geographical epistemology. Annals of the Association of American Geographers, 51, 241-260.

Lynch, K. (1960). The image of the city. Cambridge (Massachusetts): The Massachusetts Institute of Technology Press. Traducción (2008) por Enrique Luis Revol.

Millán, M. (2004). La geografía de la percepción: una metodología de análisis para el desarrollo rural. Papeles de Geografía, 40, 133-150.

Niño, D. (2015). Elementos de semiótica agentiva. Bogotá, Universidad Jorge Tadeo lozano.

Reques, P. (2006). La geografía de la percepción y del comportamiento. Actas V Jornadas Nacionales de Investigación en Psicología, Santander.

Santos, Milton. (2000). La naturaleza del espacio. Técnica y Tiempo. Razón y emoción. Barcelona, Ariel Geografía.

Tuan, Y. (1974). Topophilia. A study of environmental perception, attitudes and values. Englewood Cliffs, New Jersey. Prentice-Hall Inc., Traducción (2007) por Flor Durán de Zapata.

Vara, J. (2008). Cinco décadas de Geografía de la percepción. Ería: Revista cuatrimestral de geografía, 77, 371-384

Zotadagui, E, et al. (2012). Dimensiones de la emoción en personas con rasgos agresivos y noagresivos (tesis de especialización). Facultad de Psicología. Universidad de San Buenaventura, Bogotá. 